\title{
Proceedings of the Forty-first Meeting of the Agricultural Research Modellers' Group
}

\author{
EDITED BY
}

\author{
L. A. CROMPTON AND T. R. WHEELER
}

School of Agriculture, Policy and Development, University of Reading, Whiteknights, PO Box 237, Reading RG6 6AR, UK

This group, which is concerned with the applications of mathematics to agricultural science, was formed in 1970 and has since met at approximately yearly intervals in London for one-day meetings. The forty-first meeting of the group, chaired by Dr Derek Rose of the School of Agriculture, Food and Rural Development, University of Newcastle upon Tyne, was held in the Kohn Centre at the Royal Society, 6-9 Carlton House Terrace, London, on Friday, 3 April 2009 when the following papers were read. 


\title{
PLENARY LECTURE \\ The value of an agricultural systems modelling and LCA approach in studying the environmental impact of agriculture
}

\author{
E. AUDSLEY* \\ Natural Resources Management Centre, School of Applied Sciences, Cranfield University, Cranfield, \\ Bedfordshire MK43 OAL, UK
}

\begin{abstract}
SUMMARY
System and process modelling encapsulates our knowledge and understanding of a process. It is not interpolation. It enables us to test our understanding by stressing the model to see if it still works. We can then use our understanding to ask, 'What if?'

The question asked is important as it determines the type of model required. For example, modelling a grass drier is at the level of the agricultural system and so it involves consideration of materials, men, machinery and the business. Typically we wish to answer: 'What is the best way of applying fertilizer, herbicide, fungicide, selecting cropping, using machinery, reducing farm emissions and producing food? However, there are pitfalls associated with the construction and application of computer simulation models, particularly with regard to choice of optimization technique, and these need to be avoided.
\end{abstract}

There is a danger of using the wrong model for a given situation. Yield nitrogen response curves are a good example. One type is a one-year experiment using different levels of nitrogen; another type is long-term study such as the Broadbalk experiments undertaken at Rothamsted Research. Investigating the rate of nitrogen input to reduce leaching should use the long-term model. However, both short- and long-term models make the optimum decision after the event. In practice, the amount of nitrogen becoming available over the summer and the amount required are not known, as they depend on the weather, so it is a probabilistic model that is needed. The same applies to many weather-dependent decisions, such as fungicide application.

Optimization is a very important feature of the modelling process and it has more uses in modelling than simply finding the optimum. It checks the model for errors and it will home in on an error or refuse to go to part of the solution space. It helps check the model for validity, since if farmers are not doing what your model indicates as the best solution, is it more likely that the farmers are wrong or the model?

Traditionally, optimum meant profit, but now there are many criteria to consider. Nitrate leaching was the first to be tackled and system models showed that the response of farmers to restrictions in application was not always helpful. Often there is a long list of economic, environmental and social criteria and an equally long list of 'stakeholders'. Unless one uses hierarchical weighting there is a danger that extra weighting will be given to the longest list.

One application of agricultural system models is to study land use under alternative future scenarios, due to climate change or economic, technical and social change. Agricultural land use on a regional scale is the sum of decision-making at the farm level. A 'farm' is a soil and a climate. The system model brings together various process models to predict crop yields, soil workability, irrigation response, nitrate leaching, harvesting and sowing dates. One such model shows arable crops spreading across the UK. However, we need to consider what people need to eat, so the scenario must define the amount of production required and the model should show where this will be grown. Interestingly, this shows that various proposed future scenarios are not feasible.

Evaluating the sustainability of food supply in the UK depends heavily on environmental criteria. This phrase encapsulates the concept that we cannot simply pass the problem of producing our food on to someone else. Life Cycle Assessment (LCA) is very useful in this context as it concentrates on the functional unit per tonne of food rather than per hectare. Interestingly, LCA also brings in all the burdens of producing the food

\footnotetext{
*To whom all correspondence should be addressed. Email: e.audsley@cranfield.ac.uk
} 
back to the source, whereas the UK agriculture inventory passes machinery to industry and Brazilian soya feed for livestock to Brazil. LCA combines process models as before and quickly shows that, for example, reducing fertilizer input by $50 \%$ does not help to achieve improvements in sustainability. For livestock, such as those used for milk and meat production, it shows that food conversion ratio is the key. Once again we can construct a linear programme model, this time for UK agriculture, to gauge the extent to which livestock systems can meet various greenhouse gas emission targets. In many cases, the models suggest these targets may not be met.

Modelling of agricultural systems contributes to an ever-expanding knowledge base and such insight can help the industry meet the challenges of improved efficiency and sustainability. 


\section{ABSTRACTS OF COMMUNICATIONS}

The role of lethal and non-lethal microbes on the dynamics and persistence of agricultural pests. M. B. BONSALL. Mathematical Ecology Research Group, Department of Zoology, University of Oxford, Oxford $O X 13 P S, U K$

Microbes are widely used in agricultural practices to control pests. For instance, the application, utilization and role of Bacillus thuringiensis $(\mathrm{Bt})$ has grown rapidly particularly through biotechnological innovations to incorporate Bt insect-specific toxin genes into crop plants. Current estimates suggest that this sort of genetic modification associated with $\mathrm{Bt}$ accounts for US $\$ 7.5$ billion and in the US alone over 62.5 million hectares are now planted with GM crops. As such the widespread application of this Bt-based biotechnology could lead to unprecedented selection pressures on agricultural pests (Tabashnik et al. 2008). Understanding how agricultural pests may respond to these factors requires a pluralistic approach particularly in delineating the processes that might drive or mitigate the evolution of pest resistance to Bt. While baseline information exists on the mechanisms through which resistance might evolve to Bt-based toxins, the role of additional microbial traits (e.g. antibiotics) on the dynamics of pests is less well developed. Multiple pathogenic traits can influence the dynamics of pathogen transmission and virulence (Bonsall \& Raymond 2008) and affect pest evolution.

Here, the population and evolution of an invertebrate pest (host)-pathogen interaction (based around the interaction between Bt and the diamondback model, Plutella xylostella) will be explored in the presence of a non-lethal synergist that the pest must tolerate but which enhances pathogen infectivity. A stage-structured model (formulated as a set of delaydifferential equations) will be present to explore how host resistance evolves to different modes of infection. The framework will be extended to explore how host trade-offs in the ability to withstand infection by the pathogen and tolerate the synergist affect the likelihood of coexistence and evolution of polymorphic host strategies.

Further, the epidemiological consequences of pathogen-synergist interactions on host dynamics will be discussed. Through effects on pathogen transmission and host mass gain, investment in tolerating a non-lethal synergist can lead to highly non-linear host dynamics. Again, trade-offs underpin these patterns. Coupling pathogen yield $v$. speed of kill trade-offs in the presence of a synergist favours pathogens that have faster speeds of kill. This feedback affects the population dynamics leading to stable equilibrium. Conversely, evolutionary changes in tolerance to the synergist can lead to population cycles in the host-pathogen interaction.

The work was supported by The Royal Society and the BBSRC.

Bonsall, M. B. \& Raymond, B. (2008). Lethal pathogens, non-lethal synergists and the evolutionary ecology of resistance. Journal of Theoretical Biology 254, 339-349.

Tabashnik, B. E., Gassmann, A. J., Crowder, D. W. \& CARriere, Y. (2008). Insect resistance to Bt crops: evidence versus theory. Nature Biotechnology $\mathbf{2 6}$, 199-202.

Statistical modelling of multiple responses with repeated measures on experimental units. S. J. POWERS ${ }^{1}$, E. J. PIRIE ${ }^{2}$ AND C. NEMETH ${ }^{3}$. ${ }^{1}$ Centre for Mathematics and Computational Biology, Biomathematics and Bioinformatics Department, Rothamsted Research, Harpenden, Hertfordshire AL5 2JQ, UK, ${ }^{2}$ Centre for Sustainable Pest and Disease Management, Plant Pathology and Microbiology Department, Rothamsted Research, Harpenden, Hertfordshire AL5 2JQ, UK, ${ }^{3}$ Centre for Crop Genetic Improvement, Plant Science Department, Rothamsted Research, Harpenden, Hertfordshire AL5 2JQ, UK

When able to propose a well-defined (empirical) model over time for a single response with repeated measures from individuals (e.g. plants), a traditional approach to modelling is the two-stage method (Mead et al. 2003). Here, the same model is fitted to each individual and the estimated parameters (e.g. growth rates) are then analysed using, for example, analysis of variance (ANOVA) to account for the experimental design and assess differences between treatments.

To benefit fully from the underlying variation given all individuals, however, it is often preferable to combine the two stages using random effects (Laird \& Ware 1982) in, for example, a random coefficient model (Hand \& Crowder 1996) suitable for linear relationships. Hierarchical non-linear models are investigated by Davidian \& Giltinan (1995). Furthermore, in situations where a non-linear model is not 
appropriate, smoothing splines may be used (Verbyla et al. 1999).

When there are multiple responses from individuals, taken at the same or different times, the methodology needs further development. A simple approach, developing the method explained by Mead et al. (2003), is to consider a model for each individual's multiple responses together, before analysis of parameters. An example of this is shown in the analysis of numbers of live, cumulative diseased and cumulative dead leaves of individual oilseed rape plants from four different cultivars over thermal time, deriving from a randomized block design. As the first stage, a parsimonious piecewise linear model is selected which fits the stacked tri-variate repeatedly measured response for each plant. Secondly, the estimated parameters from this model are analysed using residual maximum likelihood (REML) (Patterson \& Thompson 1971) to account for the inconvenience of missing plants from some blocks and to allow comparison of the cultivars. The models are set up and fitted using the GenStat ${ }^{\mathbb{R}}$ (Lawes Agricultural Trust 2008) statistical system.

To provide a more comprehensive modelling of such data which combines the two stages, a method employing intra-individual effects for parameters within the responses is described. In addition, for welldefined non-linear models, if required the correlation between time points can be accounted for using a firstorder autoregressive or power-distance process as part of the error structure. A simple example is shown in the modelling of a tri-variate response of contents of three different polysaccharide constituents (Betaglucans, other glucans and Arabinoxylan) of developing grain sampled from wheat plants, using logistic curves. Although not necessary in this example, when treatments are to be compared, models with and without constraints on intra-individual effects allows the statistical significance of differences to be assessed. This provides a more robust comparison of treatments, tested using the residual variation arising from a single model of all the data rather than the residual variation at the second stage of a two-stage model.

Rothamsted Research receives grant-aided support from the BBSRC.

Davidian, M. \& Giltinan, D. M. (1995). Nonlinear Models for Repeated Measurement Data: Monographs on Statistics and Applied Probability 62. Boca Raton, FL: Chapman \& Hall.

Hand, D. \& Crowder, M. (1996). Practical Longitudinal Data Analysis. Oxford, UK: Clarendon Press.

Laird, N. M. \& Ware, J. H. (1982). Random-effects models for longitudinal data. Biometrics 38, 963974.

Lawes Agricultural Trust (2008). GenStat ${ }^{\circledR} 11$ th edn. Hemel Hempstead, UK: VSN International Ltd.
Mead, R., Curnow, R. N. \& Hasted, A. M. (2003). Statistical Methods in Agriculture and Experimental Biology, 3rd edn. Boca Raton, FL: Chapman \& Hall.

Patterson, H. D. \& Thompson, R. (1971). Recovery of inter-block information when block sizes are unequal. Biometrika 58, 545-554.

Verbyla, A. P., Cullis, B. R., Kenward, M. G. \& Welham, S. J. (1999). The analysis of designed experiments and longitudinal data by using smoothing splines. Journal of the Royal Statistical Society Series C (Applied Statistics) 48, 269-311.

Carbon management in a Scottish farmland. C. F. E. TOPP AND R. M. REES. SAC Research, West Mains Road, Edinburgh EH9 3JG, UK

British agriculture's contribution to the release of greenhouse gas emissions decreased from 0.086 in 1999 to 0.078 in 2005 (http://www.statistics.gov.uk/). However, farmers are under increasing pressure to reduce the carbon equivalent footprint of their practices. In the UK, agriculture contributes 0.67 of the total nitrous oxide $\left(\mathrm{N}_{2} \mathrm{O}\right)$ emissions and 0.37 of methane $\left(\mathrm{CH}_{4}\right)$. The measurements of carbon (C) storage in soils and $\mathrm{C}$ exchange can be made; however, they are technically demanding and difficult to repeat at a wide range of sites. There is a need for the development and deployment of simple tools to measure carbon footprints from land-based industries (Anon 2007). In this study, two contrasting models have been used to assess farm-gate greenhouse gas emissions, as carbon equivalents (Ceq), on a livestock farm in the north-east of Scotland. Environmental and management data were obtained from a mixed arable and livestock farm rearing cattle. The stocking rate is approximately one cow per ha and the cattle are fed on home-produced feed. The farmer also summer grazes sheep. Approximately 0.55 of the farm is rotational grass and cereal. The average nitrogen (N) fertilizer application rate is $169 \mathrm{~kg} \mathrm{~N} / \mathrm{ha}$ and the $50 \mathrm{~kg} \mathrm{~N} / \mathrm{ha}$ is applied as slurry or manure. The remainder of the farm is either natural grassland or natural grassland and woodland. The first approach followed the 2006 IPCC Guidelines for National Inventories (IPCC 2006) and was based on the tier 1 methodology. The second approach was the dynamic and deterministic nutrient cycling model DNDC (DeNitrificationDeComposition) (Li et al. 1992, 2006), which has been extensively applied across agro-ecosystems around the world and is widely acknowledged as a state-of-the-art model for use assessing $\mathrm{N}$ and $\mathrm{C}$ in arable and grassland farming systems. It calculates the daily changes in pool sizes and exchange of $\mathrm{C}$ and $\mathrm{N}$ from the plant and soil systems, and hence describes the flows of carbon dioxide $\left(\mathrm{CO}_{2}\right), \mathrm{N}_{2} \mathrm{O}$ and $\mathrm{CH}_{4}$. The enteric emissions were calculated using IPCC tier 1 methodology. The overall $\mathrm{C}$ budget for the farm in 2006 estimated by 
IPCC tier 1 was negative, with a removal from the atmosphere of $44 \mathrm{~kg} \mathrm{Ceq} / \mathrm{ha} / \mathrm{yr}$. This negative value resulted from a large amount of $\mathrm{C}$ uptake by the vegetation offsetting $\mathrm{CO}_{2}, \mathrm{~N}_{2} \mathrm{O}$ and $\mathrm{CH}_{4}$ releases. Both IPCC and DNDC predicted a significant $\mathrm{C}$ uptake by vegetation of 932 and $1161 \mathrm{~kg} \mathrm{Ceq} / \mathrm{ha} / \mathrm{yr}$, respectively. Emissions of $\mathrm{N}_{2} \mathrm{O}$ estimated by DNDC were larger than those by IPCC, resulting in a lower net C uptake of $694 \mathrm{~kg} \mathrm{C} / \mathrm{ha} / \mathrm{yr}$ by DNDC, and $823 \mathrm{~kg} \mathrm{C} / \mathrm{ha} / \mathrm{yr}$ by IPCC. Less than $0 \cdot 10$ of emissions were associated with on farm use of fuel, with land use and animals contributing to the remainder. Improved management of farm animals and fertilizer $\mathrm{N}$ use are likely to be the best options for lowering still further the Ceq emissions from the farm.

We are grateful to $\mathrm{Mr} \mathrm{A}$. Adams for the provision of farm data and to QMS for funding SAC staff to collate the farm data and produce the DNDC model output reported here.

Anon (2007). Part of the solution: climate change, agriculture and land management. Available online at http:// www.nfuonline.com/documents/Campaigns/Climate $\% 20$ Change\%20Report.pdf (verified 4 September 2009).

IPCC (2006). 2006 IPCC Guidelines for National Greenhouse Gas Inventories, Prepared by the National Greenhouse Gas Inventories Programme (Eds H.S. Eggleston, L. Buendia, K. Miwa, T. Ngara \& K. Tanabe). Hayama, Japan: Institute for Global Environmental Strategies.

Li, C. S., Farahbakhshazad, N., Jaynes, D. B., Dinnes, D. L., Salas, W \& Mclaughlin, D. (2006). Modelling nitrate leaching with a biogeochemical model modified based on observations in a row-crop field in Iowa. Ecological Modelling 196, 116-130.

Li, C. S., Frolking, S. \& Frolkin, T. A. (1992). A model of nitrous-oxide evolution from soil driven by rainfall events. 1. model structure and sensitivity. Journal of Geophysical Research-Atmospheres 97, 9759-9776.

Development of a web portal for plant models. R. I. MUETZELFELDT $^{1}, \quad$ H. OUGHAM ${ }^{2}$, A. MILLAR $^{3}$, C. DAVEY ${ }^{2}$ AND C. TINDAL ${ }^{3} .{ }^{1}$ Simulistics Ltd, 11 Tantallon Place, Edinburgh EH9 INZ, UK, ${ }^{2}$ Institute of Biological, Environmental and Rural Sciences, Aberystwyth University, Aberystwyth SY23 3EB, UK, ${ }^{3}$ Centre for Systems Biology at Edinburgh, The University of Edinburgh, Edinburgh EH9 3JU, UK

A large number of models have been developed over the last few decades in agricultural and ecological research. However, it is very difficult to obtain access to these models: the source code may no longer be available; their authors may have moved on; the documentation may be poor or missing, or the models may require compilers which no longer exist. A number of model catalogues have been developed, e.g. CAMASE (Plentinger \& Penning de Vries 1996) and REM (Ernst et al. 1997), but these simply present information about the model, rather than providing access to the model itself.

The BBSRC-funded PlaSMo (Plant Systems Biology Modelling) project aims to address this problem by converting legacy plant and crop models into a standard, XML-based format which is then accessible through a web portal. This involves re-implementing the models in Simile (Muetzelfeldt \& Massheder 2003), a visual modelling environment specifically developed for ecological and environmental modelling. The models are then saved in Simile's XML-based model-representation format and uploaded to the web portal, along with model metadata (such as author and publications) describing the model. Users can then search for particular models, view a model in a variety of formats using tools provided on the portal, run the models in a web browser, or download the models into Simile.

PlaSMo currently has a particular focus on plant models because it arose out of a recognition by the plant systems biology community that such models provide a valuable resource for the community as they scale up from the cell to the whole organism (GARNet 2006), with the emergent properties of the cell-level models appearing as parameters for the organism-level model. For this reason, we aim to integrate closely with the Systems Biology Markup Language (SBML, http://www.sbml.org), an XMLbased language widely used in the systems biology community for modelling biological pathways at the cell level. However, the design of the web approach itself is not at all specific to plant models and we envisage that it will rapidly grow to include models from other areas, such as epidemiology, animal husbandry, soil biology and ecology. We also expect that as the number of models grows, other groups will develop tools for building, displaying and simulating the behaviour of the models.

Ernst, E., Benz, J., Hoch, R., Sinowski, W. \& Gayler, S. (1997). Register of Ecological Models. Available online at http://citeseerx.ist.psu.edu/viewdoc/download?doi $=10.1$. 1.49.7506\&rep $=$ rep $1 \&$ type $=$ ps $\quad$ (verified 4 September 2009).

GARNET (2006). Final report of the GARNet Advisory Committee on Arabidopsis Systems Biology in the UK, June 2006. Available online at http://garnet.arabidopsis. info/GARNet_PSB_final_reportv1.pdf (verified 4 September 2009).

Muetzelfeldt, R. \& Massheder, J. (2003). The Simile visual modelling environment. European Journal of Agronomy 18, 345-358.

Plentinger, M. C. \& Penning De Vries, F. W. T. (Eds) (1996). CAMASE Register of Agro-Ecosystems Models. DLO-Research Institute for Agrobiology and Soil Fertility, Wageningen, The Netherlands. Available online at http://library.wur.nl/way/bestanden/clc/1763788.pdf (verified 4 September 2009). 
Simulating the effect on greenhouse gas emissions after implementing a trajectory towards sustainability of a dairy farm. A. DEL PRADO ${ }^{1,2}$, D. CHADWICK ${ }^{2}$ AND D. SCHOLEFIELD ${ }^{2} .{ }^{1}$ BC3-Basque Centre for Climate Change, Gran Via, 35-2, 48009 Bilbao, Spain (current address), ${ }^{2}$ North Wyke Research, Okehampton, Devon EX20 2SB, UK

This paper discusses the use of the SIMS DAIRY $_{\text {mod- }}$ elling framework (del Prado \& Scholefield 2008) to analyse the impact on greenhouse gas (GHG) emissions after setting up a trajectory to achieve sustainability in a typical dairy farm in the UK.

The whole-systems response was assessed through evaluation against a baseline dairy farm scenario. A trajectory including 13 farm improvements (steps) towards sustainability was defined. The effects of implementing this trajectory (best sequence of management improvement steps) on typical UK dairy systems on the GHG emissions and sustainabilityassociated side-effects were simulated and analysed. Each successive step incorporated all previous steps and the SIMS DAIRY $_{\text {optimization procedure, for }}$ most parameters, was set to adjust the hectares required for forage production. Farm changes at each step included measures at the management level and at the genetic level of plants and animals. Desirable targets for pollution compared with baseline farms were set. These included, for example, compliance with EU Nitrate Directive $(<11.3 \mathrm{mg} \mathrm{N} / 1$ in the leachate) and GHG reduction from baseline according to Kyoto protocol targets $(15 \%)$, both individually and as a whole. Thresholds were also defined for other sustainability indices, for example, biodiversity.

Desired targets for pollution sustainability were generally met on the last step. Targets related to potential eutrophication were met in all cases for $\mathrm{NO}_{3}^{-}$ leaching, except for some extended systems in drier areas. Those targets related to potential impacts on the climate change by production of GHG were met in all cases for methane $\left(\mathrm{CH}_{4}\right)$ and in almost all cases for nitrous oxide $\left(\mathrm{N}_{2} \mathrm{O}\right)$, except for some fully housed systems. Farms on heavier soils generally showed greater scope to reduce $\mathrm{N}_{2} \mathrm{O}$ emissions from soils than those on lighter ones. However, lighter soils resulted in much lower absolute values of $\mathrm{N}_{2} \mathrm{O}$ losses per hectare than heavier soils. Although changes in the diet were sufficient in all cases to reduce $\mathrm{CH}_{4}$ losses to the targeted values, these reductions were in all cases more modest than those predicted for $\mathrm{N}_{2} \mathrm{O}$ emissions. Therefore, measures to reduce GHG output should be prioritized towards those targeted at limiting $\mathrm{N}_{2} \mathrm{O}$ emissions. Ammonia losses were generally reduced through management and $\mathrm{NO}_{x}$ losses reduced through improvements in the silage and fertilizer management. Milk quality targets were met in almost all cases. Landscape, biodiversity and soil quality targets were seldom met and the scope for animal welfare and net farm income targets to be met varied with and within systems and sites.

Del Prado, A. \& Scholefield, D. (2008). Use of SIMS $_{\text {DAIRY }}$ modelling framework system to compare the scope on the sustainability of a dairy farm of animal and plant genetic-based improvements with managementbased changes. Journal of Agricultural Science, Cambridge 146, 195-211.

BulkDry/BulkCool-models for knowledge transfer. D. J. PARSONS ${ }^{1}$, K. PEARN ${ }^{1}$, D. BRUCE ${ }^{2}$, D. ARMITAGE $^{3,4}$, D. COOK $^{4}$ AND T. WONTNERSMITH $^{4}$. ${ }^{1}$ Cranfield University, Cranfield, Bedfordshire MK43 OAL, UK, ${ }^{2}$ David Bruce Consulting Ltd, 54 High Road, Shillington, Hitchin, Bedfordshire $\quad S G 5 \quad 3 L L, \quad U K,{ }^{3}$ Independent Consultant/CSL Fellow, ${ }^{4}$ Central Science Laboratory, Sand Hutton, York YO41 1LZ, UK

BulkDry is an interactive simulation of near-ambient, deep-bed drying of wheat and barley intended for use as a knowledge transfer tool to communicate the principles of drier management. It was released in its present form in 2007, based on similar tools originally developed in 1984, and has been used successfully at several events. It is based on an equilibrium model of grain drying (Morey et al. 1979). The model considers the grain bed as a set of 15 homogeneous horizontal layers through which air is blown upwards. Within each $1 \mathrm{~h}$ time step it is assumed that the air passing through a layer will reach a moisture and temperature equilibrium with the grain in the layer, so that the air leaving the bed is at the equilibrium relative humidity (RH) corresponding to the moisture content of the grain. The equilibrium is determined by empirically derived isotherms for adsorption and desorption. The model is driven by hourly weather data, and a variety of control strategies may be employed, including $\mathrm{RH}$ set points for the fan and an optional heater or dehumidifier. It includes an empirical model of the risk of spoilage (mycotoxin formation): the grain must reach the target moisture content before spoilage occurs.

Two new programs were developed based on the same model. BulkDry for Oilseed Rape was a straightforward reparameterization for a different crop. The main changes were to the isotherms and the relationship between pressure and ventilation rate. BulkCool extended the model to cooling of cereals or rapeseed following drying in order to prevent the reproduction of invertebrate pests. Although the physical model was essentially the same, systematic errors were found compared with experimental data and a more comprehensive model, known as Storedry 
(Sharp 1984), resulting in cooling times to reach $0 \cdot 10$ of the initial difference from ambient that were up to $80 \%$ greater. Two modifications were needed. First, sensible heat exchange was not required in the drying model, because latent heat transfer is dominant during drying. However, there is little or no evaporation during the cooling of dry grain, so sensible heat transfer dominates and was added to the model. Second, due to the slow rates of change, the number of layers had to be increased from 15 to 100 . With these changes the cooling times were identical to Storedry. These two models are being released in spring 2009 and all three will be freely available from the HomeGrown Cereals Authority (HGCA) web site.

This work was funded by HGCA.

Morey, R. V., Cloud, H. A., Gustafson, R. J. \& Petersen, D. W. (1979). Evaluation of the feasibility of solar energy grain drying. Transactions of the American Society of Agricultural Engineers 22, 409-417.

Sharp, J. R. (1984). The design and management of low temperature grain driers in England - a simulation study. Journal of Agricultural Engineering Research 29, 123-131.

\section{Theoretical evaluation of pyramided and sequential deployment of resistance genes using a yield-related measure of durability of cultivar resistance. I. DEMON AND F. VAN DEN BOSCH. Rothamsted Research, Harpenden, Hertfordshire AL5 2JQ, UK}

The rapid genetic changes occurring in pest and pathogen species have disrupted the balance between the introduction of novel pesticides/fungicides and the development of insensitivity to these products by pests/pathogens (Kiyosawa 1982; Nauen \& Denholm 2005). For that reason and environmental considerations the emphasis of pathogen control has shifted to crop resistance breeding. The key problem of using resistant cultivars is that resistance genes exert selection pressures on the pathogen to evolve virulent strains, leading to the often rapid resistance breakdown (Sprague et al. 2006). To increase the durability of cultivar resistance, several deployment strategies for resistance genes have been considered (McDonald $\&$ Linde 2002a). Pyramiding of multiple genes into a single cultivar is often advocated as a deployment strategy to increase the durability of resistance. However, empirical evidence for it working in practice is limited and often inconclusive; therefore, there is a requirement for theoretical underpinning (McDonald \& Linde 2002b). The durability of resistance obtained for pyramided deployment was investigated under the assumption of a fitness cost incurred by the pathogen associated with overcoming resistance genes. For comparison, sequential deployment of resistance genes was also considered. As yield gain is the key objective of resistance gene deployment, the additional yield obtained from deploying resistance genes as the measure for durability of resistance was utilized (van den Bosch \& Gilligan 2003). Although the work is of a generic nature, the terminology relating to plant pathogen systems is used and an epidemiological model describing a pathosystem into which resistance genes are introduced is developed. A single strain of an avirulent pathogen was assumed and that virulence develops through mutation and migration of virulence from outside the pathosystem. It was shown that, when virulence is present in the genetic background of the pathogen population, pyramiding is often not the best strategy to maximize the yield gain from deploying resistance genes. It was also shown, when the resistance genes are deployed sequentially, that selection and mutation affect the genetic composition of the pathogen population with unexpected consequences for the relation between yield gain and the fraction of fields planted with the resistant cultivar. Additionally, it was shown that the difference between the cost of virulence of pathogen strains with one virulence factor and strains with two virulence factors determines whether pyramided or sequential deployment generates the largest yield gain.

Kiyosawa, S. (1982). Genetics and epidemiological modelling of breakdown of plant disease resistance. Annual Review of Phytopathology 20, 93-117.

McDonald, B. A. \& Linde, C. (2002a). Pathogen population genetics, evolutionary potential, and durable resistance. Annual Review of Phytopathology 40, 349-379.

McDonald, B. A. \& Linde, C. (2002b). The population genetics of plant pathogens and breeding strategies for durable resistance. Euphytica 124, 163-180.

Nauen, R. \& Denholm, I. (2005). Resistance of insect pests to neonicotinoid insecticides: current status and future prospects. Archives of Insect Biochemistry and Physiology 58, 200-215.

Sprague, S. J., Marcroft, S. J., Hayden, H. L. \& Howlett, B. J. (2006). Major gene resistance to blackleg in Brassica napus overcome within three years of commercial production in south-eastern Australia. Plant Disease 90, 190-198.

VAn den Bosch, F. \& Gilligan, C. A. (2003). Measures of durability of resistance. Phytopathology 93, 616-625.

\section{Application of triangular distributions in a data-limited environment. $M$. ITUMOH, P. WILSON AND S. RAMSDEN. Division of Agricultural and Environmental Sciences, School of Biosciences, Uni- versity of Nottingham, Sutton Bonington Campus, Loughborough, Leicestershire LE12 5RD, UK}

Agriculture in the Ebonyi State region of Nigeria consists of a large number of small farms growing a diverse range of crops. Available data on crop yields and prices show that both vary considerably over time, and management of this instability is an important concern of farmers. However, the value of 
these data is limited: the number of observations may be small, the scale may be national rather than local and the data may not cover the full range of crops grown by farmers. At the local level, survey information (e.g. Itumoh 2008) can potentially give a better indication of the variability of crop returns; however, farmers are often unable to give accurate estimates of yield. Alternatively, crop models can be used to generate yields under simulated weather conditions. Again, data are often a limiting factor: e.g. calibration data for tropical crops are often scarce.

In data-limited situations, Hardaker et al. (2004) recommend using triangular distributions, requiring maximum, minimum and modal data values. For Ebonyi State, these were derived from a farm survey conducted in 2004 for cassava, maize, rice, yam and bambara groundnut. For each crop, 10 years of realterms price data were obtained from the Food and Agriculture Organization. Prices and yields were assumed to be independent; however, a strong positive correlation between movements in prices over time for the five crops exists. To explore crop-price linkages, a baseline crop price (rice, $P_{\mathrm{r}}$ ) was used to estimate individual crop prices $\left(P_{\mathrm{c}}^{*}\right)$ on the basis of known crop prices $\left(P_{\mathrm{c}}\right)$ and the correlation $\left(r_{\mathrm{c}}\right)$ between each $P_{\mathrm{c}}$ and $P_{\mathrm{r}}$ :

$$
P_{\mathrm{c}}^{*}=\left[r_{\mathrm{c}}\left(\left(P_{\mathrm{c}} / P_{\mathrm{r}}\right) P T D_{\mathrm{r}}\right)\right]+\left[P T D_{\mathrm{c}}\left(1-r_{\mathrm{c}}\right)\right]
$$

where $P T D_{\mathrm{r}}$ is the randomly generated real price of rice, $P T D_{\mathrm{c}}$ is the randomly generated real price of crop c, and $P T D_{\mathrm{r}}$ and $P T D_{\mathrm{c}}$ are generated from the relevant triangular distributions. One hundred draws were used to generate 100 estimates of $P_{\mathrm{c}}^{*}$ and these were used with yield estimates generated from the relevant yield triangular distributions to give 100 estimates of gross margin variability (variable costs were assumed to remain constant). As an application of the approach, covariance matrices were generated for use in a quadratic programming model to produce expected profit and variability of profit frontiers for farms in Ebonyi province. The frontiers show the trade-off between profit and variability of profit, a major source of risk to small-scale farmers, and help to assess the extent to which price and yield variability can be managed through crop diversification.

Hardaker, J. B., Huirne, R. B. M., Anderson, J. R. \& Lien, G. (2004). Coping with Risk in Agriculture, 2nd edn. Wallingford, UK: CAB International.

Iтимон, M. O. (2008). Decision aid for resource management in Ebonyi State (Nigeria) small-scale agriculture. $\mathrm{PhD}$ Thesis, University of Nottingham, UK.

\footnotetext{
A numerical optimization method to estimate the spatial distribution of an epidemic. S. R. PARNELL ${ }^{1}$, T. R. GOTTWALD ${ }^{2}$ AND F. VAN DEN BOSCH ${ }^{1}$.
}

${ }^{1}$ Rothamsted Research, Harpenden, Hertfordshire AL5 2JQ, UK, ${ }^{2}$ US Department of Agriculture, Agricultural Research Service, Ft. Pierce, FL 34945, USA

Information on the spatial distribution of an epidemic is crucial for effective disease management. For example, a disease map can facilitate the deployment of spatially targeted control measures such as field spray applications in precision agriculture (Fleischer et al. 1999) or host removals during a disease eradication programme (Ferguson et al. 2001; Gottwald 2007). Due to economic and logistical constraints it is not normally possible to conduct a complete census of an area from which to construct a disease map. Therefore, an incomplete sample is taken and inferences of disease status at un-sampled locations must be made. In plant disease epidemiology this has frequently been done using spatial interpolation methods, such as kriging, from the field of geostatistics (Nelson et al. 1999). These methods originate in mining and mineral exploration and work by estimating a continuous surface map from a set of point samples. This is a useful approximation when the variate to be mapped is continuous in space. However, in epidemiological applications the host distribution is often non-contiguous and heterogeneous and this can have a significant influence on the spatial distribution of disease. For example, the transmission of many diseases is constrained to neighbouring areas, therefore, distinct patches of hosts can be connected by the existence of several smaller host patches (i.e. a stepping stone effect). Here we introduce an epidemiologically motivated optimization procedure which estimates the probability of disease at un-sampled host locations by incorporating information on the host distribution and characteristics of local pathogen transmission. We demonstrate this generic method using two examples from plant disease epidemiology, citrus canker and Huanglongbing (Gottwald 2007), and show how the accuracy of the estimated maps relates to sample size and sample placement.

Rothamsted Research receives support from the Biotechnology and Biological Sciences Research Council.

Ferguson, N. M., Donnelly, C. A. \& Anderson, R. M. (2001). The foot-and-mouth epidemic in Great Britain: pattern of spread and impact of interventions. Science 292, 1155-1160.

Fleischer, S. J., Blom, P. E. \& Weisz, R. (1999). Sampling in precision IPM: when the objective is a map. Phytopathology 89, 1112-1118.

GotTwald, T. R. (2007). Citrus canker and citrus Huanglongbing, two exotic bacterial diseases threatening the citrus industries of the Western Hemisphere. Outlooks on Pest Management 18, 274-279.

Nelson, M. R., Orum, T. V., Jamie-Garcia, R. \& Nadeem, A. (1999). Applications of geographic information 
systems and geostatistics in plant disease epidemiology and management. Plant Disease 83, 308-319.

\section{Understanding the past and predicting the future with historical variety trial data. I. MACKAY,} H. PHILPOTT, A. HORWELL, J. GARNER, J. WHITE AND J. MCKEE. National Institute of Agricultural Botany, Huntingdon Road, Cambridge CB3 OLE, UK

Analysis of data from variety evaluation trials collected over many years represents a valuable resource for the evaluation of interaction between genotype and environmental variables. For example, analyses published for such data, collected in the period 1947-78 (Silvey 1978, 1981, 1986), showed genetic gain (independent of substantial gains due to changes in husbandry) in wheat, barley and oats to be 65,32 and $25 \%$, respectively. This analysis has now been extended for wheat and barley to include all years up to 2007 and analysed by mixed-effect models using computational power that was not available to Silvey who was limited to using 5 -year rolling means. The advances in statistical methods and computing power mean that it is now possible to analyse a whole series of trials from over 60 years as a single dataset to derive estimates of relative variety performance. For winter wheat, this encompasses about 53000 data points from 3600 trials for over 400 varieties tested in a minimum of 3 years. Aside from the difference in scale, the analytical methods are the same as those used to derive recommended lists by analysing 3- to 5 -year datasets. NIAB have then followed Silvey's approach in relating trial performance to national yields by using historical records held by DEFRA, coupled with NIAB seed certification figures (which give an estimate of the national variety mix in any year). For wheat and barley, we are able to demonstrate that the contribution to yield increase has, in the last 25 years, been almost exclusively from improved genotype. For the period 1982-2007, 0.93 of the increase in winter wheat yields are due to variety, the figures for spring and winter barley are 0.87 and 0.92 respectively. This reflects optimization of agronomic practice in the 1980s and 1990s and the more recent trend to targeted application of agrochemicals aimed at maximizing gross margin and minimizing environmental impact. A complementary analysis of trials data for some non-cereal species (oilseed rape, sugar beet and maize) provides an interesting contrast to the cereals. All the crops analysed show a positive influence of variety on trial yields over the last 25 years. The effect of non-genetic factors on oilseed rape trial yields has declined over the period, whereas for sugar beet and maize trials, yield increases can be attributed to a combination of variety and nongenetic factors.
A central element of mixed effects modelling is the prediction of performance of varieties in years and locations where they were never sown. In this context, we believe our database and modelling methodology could be extended to include meteorological data for the specific sites and years where the trials were grown. With these variables included in the model we would be able to estimate the future impact of climate change on agricultural production and identify historic varieties best suited to anticipated climatic change. Such information could inform future breeding strategies and might also guide farmer's choice of variety today.

In conclusion, we show that improved genotype has been almost the only source of agronomic gain in the past 20 years for wheat and barley and that historic data have the potential to help breeders and farmers to anticipate and respond to the new genotype $\times$ climate interactions we predict in the next 50 years.

Silvey, V. (1978). The contribution of new varieties to increasing cereal yield in England and Wales. Journal of the National Institute of Agricultural Botany 14, 367-384.

SiLvey, V. (1981). The contribution of new wheat, barley and oat varieties to increasing yield in England and Wales 1947-78. Journal of the National Institute of Agricultural Botany 15, 399-412.

SILVEY, V. (1986). The contribution of new varieties to cereal yields in England and Wales between 1947 and 1983. Journal of the National Institute of Agricultural Botany 17, $155-168$.

Silvey, V. (1994). Plant breeding in improving crop yield and quality in recent decades. Acta Horticulturae $\mathbf{3 5 5}$, 19-34.

\section{Discontinuous host growth and the evolution of plant pathogens. F. VAN DEN BERG AND F. VAN DEN BOSCH. Department of Biomathematics and Bioinformatics, Rothamsted Research, Harpenden, Hertfordshire AL5 2JQ, UK}

The evolutionary responses of plant pathogens to the use of fungicides and/or resistant crops have been intensively studied. The selection pressures imposed on the evolution of a pathogen's life-cycle characteristics by other disease management strategies or changes in the environment have been studied much less frequently. Such adaptations can, however, have a major effect on epidemic dynamics and therewith host performance. This presentation aims to give an overview of theoretical and experimental approaches currently being undertaken in a BBSRC-INRA collaboration aimed at understanding the effect of discontinuous host growth on the evolution of pathogen life cycle characteristics.

Many natural and agricultural ecosystems are characterized by periodic host absence. These periods 
of host absence are often relatively large and are known to have profound effects on the dynamics of parasite populations (Gubbins \& Gilligan 1997; Caswell 2001; Altizer et al. 2006; Olinky et al. 2008). However, little is known about the selection pressures such seasonality might impose on a parasite's lifecycle characteristics.

We have shown that periods of host absence can indeed put a strong selection pressure on the pathogen and that the effect a period of host absence has is different for airborne pathogens as compared to soilborne pathogens. The key findings are evidence of a trade-off between latent period and sporulation capacity for Puccinia triticina, i.e. leaf rust of wheat; evidence of a trade-off between infection efficiency and inoculum survival in the absence of the host for Gaeumannomycus graminis, i.e. take-all of wheat; seasonal trade-off in combination with a model for discontinuous host growth cannot explain the coexistence of two genetically distinct phenotypes of take-all of wheat and increased periods of host absence seem to select for a higher reproductive capacity in airborne pathogens, yet a lower reproductive capacity in soil-borne pathogens.

Rothamsted Research receives support from the Biotechnology and Biological Sciences Research Council of the United Kingdom. This work was part of an INRA/ BBSRC-funded project entitled 'Epidemiological and evolutionary models for invasion and persistence of disease'.

Altizer, S., Dobson, A., Hosseini, P., Hudson, P., Pascual, M. \& Rohani, P. (2006). Seasonality and the dynamics of infectious diseases. Ecology Letters $\mathbf{9}$, $467-484$

Caswell, H. (2001). Matrix Population Models: Construction, Analysis and Interpretation, 2nd edn. Sunderland, MA: Sinauer Associates Inc.

Gubbins, S. \& Gilligan, C. A. (1997). Biological control in a disturbed environment. Philosophical Transactions of the Royal Society London B 352, 1935-1949.

Olinky, R., Huppert, A. \& Stone, L. (2008). Seasonal dynamics and thresholds governing recurrent epidemics. Journal of Mathematical Biology 56, 827-839.

Predicting methane emissions and nitrogen excretion from cattle. J. A. N. MILLS ${ }^{1}$, L. A. CROMPTON ${ }^{1}$, A. BANNINK ${ }^{2}$, S. TAMMINGA ${ }^{3}$ J. M. MOORBY ${ }^{4}$ AND C. K. REYNOLDS ${ }^{1}{ }^{1}$ Animal Science Research Group, School of Agriculture, Policy and Development, University of Reading, Whiteknights, PO Box 237, Reading RG6 6AR, UK, ${ }^{2}$ Livestock Research, Animal Sciences Group, Wageningen University Research Centre, PO Box 65, 8200 AB, Lelystad, The Netherlands, ${ }^{3}$ Animal Nutrition Group, Wageningen Institute of Animal Science, Wageningen University, Marijkeweg 40, 6709 PG, Wageningen, The Netherlands, ${ }^{4}$ Institute of Biological, Environmental and Rural Sciences,
Aberystwyth University, Gogerddan, Aberystwyth, Ceredigion $S Y 23$ 3EB, UK

As a foundation for further research to develop new ruminant nutrition regimens for simultaneously reducing methane emissions and nitrogen excretion in growing and lactating ruminants, a meta-analysis of existing data was undertaken. Measurements of energy and/or nitrogen balance obtained using respiration calorimetry and digestion trials were accumulated into a database for meta-analysis of effects of key parameters on both methane and nitrogen excretion in growing and lactating beef cattle and lactating and non-lactating dairy cows. An existing database of individual measurements of energy and nitrogen balance from the University of Reading, which included measurements of methane and nitrogen excretion, was updated and expanded using more recent data from Reading and existing data from other laboratories. Additional data were obtained from the USA, Wales and the Netherlands, giving a total of 1819 individual measurements (1335 records of methane excretion). A multivariate analysis was conducted using the Mixed Models procedures of SAS (SAS Institute Inc., Cary, NC) and linear regression models as described by St-Pierre (2001). Adjustments were made for variance associated with location and trial effects, to determine the most important dietary factors that influence methane and nitrogen excretion, based on both linear and nonlinear models. As observed in previous studies with smaller databases (Mills et al. 2003), total feed dry matter intake (DMI) has an overriding effect on the amount of methane produced by cattle, across a broad range of diet types and productive states. The prediction of methane production is improved only slightly on the basis of digestible energy, which is an indicator of the amount of organic matter fermented in the diet fed. In addition to DMI, the concentration of starch relative to that of acid detergent fibre (ADF) had a significant effect on the amount of methane produced, with increasing ratios of starch to ADF causing a decline in the release of methane per unit of DMI. However, the effect of increasing amounts of starch relative to fibre was curvilinear and less pronounced at higher levels of starch feeding typical of rations fed to finishing beef cattle in the USA. Lower producing animals tend to lose more feed energy as methane per unit of milk produced. This is especially true at very low levels of milk yield, as observed in lactating beef cows. Therefore, the research demonstrates that a static estimate of the proportion of feed energy lost as methane is inappropriate. However, a reliable estimate of methane emissions can be obtained for both beef and dairy animals if information on DMI is available. 
Nitrogen intake is the principal driver of nitrogen excretion, although the level of intake with respect to requirement modifies the response. As nitrogen intake relative to requirement increases, the proportion of total nitrogen excreted increases at a slower rate than nitrogen excreted as urinary nitrogen. In contrast to the results of Castillo et al. (2001) the increase in urinary nitrogen excretion remained linear with increasing nitrogen intake. In this large population of measurements, nitrogen excretion was relatively unaffected by the balance between structural (fibre) and non-structural (starch) carbohydrate. On average, lower producing animals excrete more nitrogen to the environment per unit of nitrogen intake, but there is much variation in nitrogen excretion relative to milk yield. Nitrogen excretion in urine and faeces can be estimated based on nitrogen intake alone.
The financial support of the Milk Development Council of England Wales (MDC 07/04/A) and the UK Department for Environment Food and Rural Affairs (DEFRA AC0209) are gratefully acknowledged.

Castillo, A. R., Kebreab, E., Beever, D. E., Barbi, J. H., Sutton, J. D., Kirby, H. C. \& France, J. (2001). The effect of protein supplementation on nitrogen utilization in lactating dairy cows fed grass silage diets. Journal of Animal Science 79, 247-253.

Mills, J. A. N., Kebreab, E., Yates, C. M., Crompton, L. A., Cammell, S. B., Dhanoa, M. S., Agnew, R. E. \& France, J. (2003). Alternative approaches to predicting methane emissions from dairy cows. Journal of Animal Science 81, 3141-3150.

St-Pierre, N. R. (2001). Integrating quantitative findings from multiple studies using mixed model methodology. Journal of Dairy Science 84, 741-755. 